\title{
Analysis on heat transfer and start-up performance of mercury heat pipe
}

\author{
Xiuxiang Zhang ${ }^{1}$, Kang $\mathrm{He}^{1, *}$, Quan Yang $^{1}$, Chengcai $\mathrm{Xi}^{2}$ \\ ${ }^{1}$ Suzhou University, Suzhou, Anhui 234000, China \\ ${ }^{2}$ Anhui ROOT Industrial Co.,Ltd., Anhui 234000, China
}

\begin{abstract}
Mercury heat pipe has the advantages of good thermal stability and low saturated vapor pressure, which is the best choice for the transition from water heat pipe to liquid metal heat pipe. The effects of heating power and heat pipe structure on start-up time and steady-state heat transfer performance of mercury heat pipe were studied by using transient thermal network model. The results showed that: 1) Increasing the length of condenser is beneficial to reducing the start-up time and thermal resistance; 2) Increasing the heating power or wall thickness will reduce the thermal resistance, but increase the start-up time, and increasing the porosity of wick is just the opposite; 3) Increasing the thickness of wick can increase both the start-up time and the thermal resistance.
\end{abstract}

\section{Introduction}

Heat pipe is one of the most effective heat transfer device and It can transfer a large amount of heat through a small cross-section area over a long distance without any additional external power, which is widely used in the fields of Electronics[1], chemical industry[2-3], aerospace[4-5] and deep space exploration[6-7]. In recent years, many researchers have done a lot of research on the performance of heat pipe. Anand studied the effect of evaporator length on the maximum heat transport of ammonia heat pipe. It was found that the longer the evaporator, the smaller the critical heat flux[8]. Miao et al. found that the critical heat flux increases with the increase of cooling temperature for bent water heat pipe[9]. Zhang et al. studied the isothermal characteristics and start-up performance of gravity cesium heat pipe at constant temperature. It was found that when the heating temperature is in the range of $330{ }^{\circ} \mathrm{C} \sim 630^{\circ} \mathrm{C}$, the higher the temperature of the heating furnace, the faster the startup of the heat pipe[10]. Wang et al. investigated the effect of heating power on the thermal resistance of potassium heat pipe. It was demonstrated that with the increase of heating power, the thermal resistance of potassium heat pipe first decreases and then increases[11]. Teng et al. analyzed the start-up and heat transfer performance of sodium heat pipe under swing conditions[12]. Tournier and El-Genk discovered that when the lithium heat pipe reaches steady state, the wall temperature near the end of condenser drops sharply by $450 \mathrm{~K}[13]$.

In a word, these studies mainly focus on whether the start-up of heat pipe can be carried out, the critical heat flux and the steady-state heat pipe thermal resistance, while the study on the start-up time of heat pipe is rare, especially for the mercury heat pipe. In this paper, the start-up time and thermal resistance of mercury heat pipe are studied by using transient thermal network and the result can provide reference for the design of mercury heat pipe.

\section{Theoretical models[14]}

Mercury heat pipe is divided into evaporator section, adiabatic section and condenser section. Each section is composed of heat pipe wall section, wick section and steam chamber section. The thermal resistance of mercury heat pipe is considered to be the result of series and parallel connection of a series of thermal resistances. Fig. 1 shows a network system for the mercury heat pipe operation, a) shows a heat transfer sketch of heat pipe and b) shows a heat transfer simplified network model of heat pipe. Since mercury heat pipe can form continuous flow at room temperature, the thermal resistance of steam chamber is very small and it can be ignored.

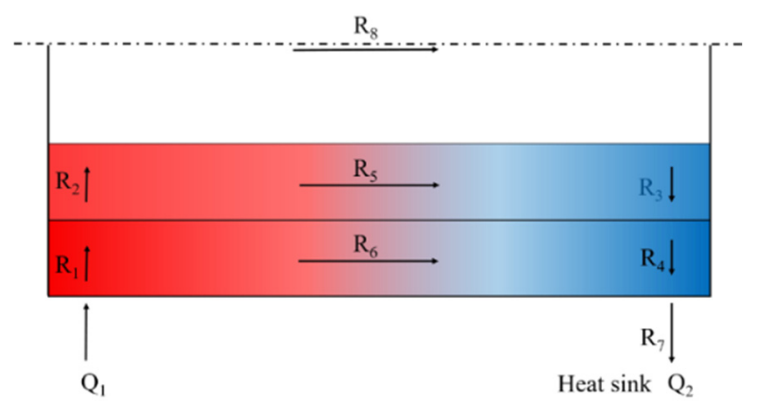

a) A heat transfer sketch of heat pipe

* Corresponding author's e-mail: 1980 evil@163.com. 


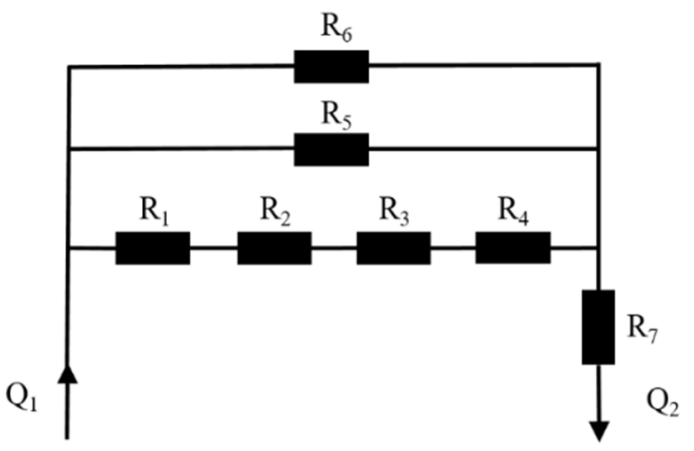

b) Schematic diagram of heat pipe implified network model

Fig.1. A network system for the mercury heat pipe operation

where $\mathrm{R} 1$ represents the radial thermal resistance of the evaporator, $\mathrm{R} 2$ represents the radial thermal resistance of wick in evaporator, R3 represents the radial thermal resistance of wick in condensator, $\mathrm{R} 4$ represents the radial thermal resistance of heat pipe wall in condenser, R5 represents the axial thermal resistance of wick in insulation section, R6 represents the axial thermal resistance of heat pipe wall in insulation section, R7 represents the convective thermal resistance in condensator, and $\mathrm{R} 8$ represents the thermal resistance of steam chamber.

Assuming that the temperature of each part of the heat pipe is uniform and expressed by T1-T7, energy conservation is applied to them and shown in Eqs. (1-4) respectively.

$$
\begin{gathered}
\rho_{\mathrm{i}} A_{i} \delta_{\mathrm{i}} c_{p, i} \frac{d T_{i}}{d t}=Q_{i, 1}-Q_{i, 2} \\
\mathrm{Q}_{i, 1}=\lambda_{i} A_{i} \frac{T_{i, 1}-T_{i}}{\delta_{i} / 2} \\
\mathrm{Q}_{i, 2}=\lambda_{i} A_{i} \frac{T_{i}-T_{i, 2}}{\delta_{i} / 2} \\
\frac{d T_{i}}{d t}=\frac{2 \alpha_{i}}{\delta_{i}^{2}}\left(T_{i, 1}+T_{i, 2}-2 T_{i}\right)
\end{gathered}
$$

Where $\rho_{i}$ represents the density of the part $i, \mathrm{~kg} / \mathrm{m} 3$; $A_{i}$ represents the cross-sectional area of the part $i, \mathrm{~m} 2$; $\delta_{i}$ represents the thermal conductivity thickness of the part $i, \mathrm{~m} ; c_{p, i}$ represents the constant pressure specific heat capacity of the part $i, \mathrm{~J} /(\mathrm{kg} \cdot \mathrm{K}) ; T_{i}$ represents the temperature of the part $i,{ }^{\circ} \mathrm{C} ; t$ represents the time, s; $Q_{i, 1}$ represents the input power of the part $i, \mathrm{~W} ; Q_{i, 2}$ represents the output power of the part $i, \mathrm{~W} ; \lambda_{i}$ represents the thermal conductivity of the part $i, \mathrm{~W} /$ (m $\cdot \mathrm{K}) ; T_{i, 1} 、 T_{i, 2}$ represents the front temperature and the rear temperature along the heat conduction direction of the part $i$ respectively, $\mathrm{K} ; \alpha_{i}$ represents the thermal diffusivity of the part $i$.

Energy conservation equations are established for seven parts of mercury heat pipe, as shown in Eqs. (5-10) respectively.

$$
\begin{aligned}
& \frac{d T_{1}}{d t}= \frac{2 \alpha_{1}}{\delta_{1}^{2}}\left[\left(\xi_{12}+\eta_{1}-2\right) \mathrm{T}_{1}+\xi_{21} T_{2}+\eta_{5} T_{5}+\eta_{6} T_{6}\right] \\
&+\frac{2 \alpha_{1}}{\delta_{1}^{2}} \frac{Q_{1} / 2}{\lambda_{1} A_{1} / \delta_{1}+\lambda_{5} A_{5} / \delta_{5}+\lambda_{6} A_{6} / \delta_{6}} \\
& \frac{d T_{2}}{d t}= \frac{2 \alpha_{2}}{\delta_{2}^{2}}\left[\xi_{12} \mathrm{~T}_{1}+\left(\xi_{21}+\xi_{23}-2\right) T_{2}+\xi_{32} T_{3}\right] \\
& \frac{d T_{3}}{d t}=\frac{2 \alpha_{3}}{\delta_{3}^{2}}\left[\xi_{23} \mathrm{~T}_{2}+\left(\xi_{32}+\xi_{34}-2\right) T_{3}+\xi_{43} T_{4}\right] \\
& \frac{d t}{d t}=\frac{2 \alpha_{4}}{\delta_{4}^{2}}\left[\xi_{34} \mathrm{~T}_{3}+\left(\xi_{43}+\eta_{4}-2\right) T_{4}+\eta_{5} T_{5}+\eta_{6} T_{6}\right] \\
&+\frac{2 \alpha_{4}}{\delta_{4}^{2}} \frac{h_{\infty, c} S_{c} T_{\infty, c} / 2}{\lambda_{4} A_{4} / \delta_{4}+\lambda_{5} A_{5} / \delta_{5}+\lambda_{6} A_{6} / \delta_{6}+h_{\infty, c} S_{c} / 2}
\end{aligned}
$$$$
\frac{d T_{5}}{d t}=\frac{2 \alpha_{5}}{\delta_{5}^{2}}\left[\eta_{1} \mathrm{~T}_{1}+\eta_{4}^{\prime} T_{4}+\left(\eta_{5}+\eta_{5}^{\prime}-2\right) T_{5}+\left(\eta_{6}+\eta_{6}^{\prime}\right) T_{6}\right]
$$$$
+\frac{2 \alpha_{5}}{\delta_{5}^{2}} \frac{Q_{1} / 2}{\lambda_{1} A_{1} / \delta_{1}+\lambda_{5} A_{5} / \delta_{5}+\lambda_{6} A_{6} / \delta_{6}}
$$$$
+\frac{2 \alpha_{5}}{\delta_{5}^{2}} \frac{h_{\infty, c} S_{c} T_{\infty, c} / 2}{\lambda_{4} A_{4} / \delta_{4}+\lambda_{5} A_{5} / \delta_{5}+\lambda_{6} A_{6} / \delta_{6}+h_{\infty, c} S_{c} / 2}
$$$$
\frac{d T_{6}}{d t}=\frac{2 \alpha_{6}}{\delta_{6}^{2}}\left[\eta_{1} \mathrm{~T}_{1}+\eta_{4}^{\prime} T_{4}+\left(\eta_{5}+\eta_{5}^{\prime}\right) T_{5}+\left(\eta_{6}+\eta_{6}^{\prime}-2\right) T_{6}\right]
$$$$
+\frac{2 \alpha_{6}}{\delta_{6}^{2}} \frac{Q_{1} / 2}{\lambda_{1} A_{1} / \delta_{1}+\lambda_{5} A_{5} / \delta_{5}+\lambda_{6} A_{6} / \delta_{6}}
$$$$
+\frac{2 \alpha_{6}}{\delta_{6}^{2}} \frac{h_{\infty, c} S_{c} T_{\infty, c} / 2}{\lambda_{4} A_{4} / \delta_{4}+\lambda_{5} A_{5} / \delta_{5}+\lambda_{6} A_{6} / \delta_{6}+h_{\infty, c} S_{c} / 2}
$$

$\xi_{i j}, \eta_{i}$ and $\eta_{i}^{\prime}$ are shown in Eqs. (11-13) respectively.

$$
\begin{aligned}
& \xi_{i j}=\frac{\lambda_{i} A_{i} / \delta_{i}}{\lambda_{i} A_{i} / \delta_{i}+\lambda_{j} A_{j} / \delta_{j}} \\
& \eta_{i}=\frac{\lambda_{i} A_{i} / \delta_{i}}{\lambda_{1} A_{1} / \delta_{1}+\lambda_{5} A_{5} / \delta_{5}+\lambda_{6} A_{6} / \delta_{6}} \\
& \eta_{i}^{\prime}=\frac{\lambda_{i} A_{i} / \delta_{i}}{\lambda_{4} A_{4} / \delta_{4}+\lambda_{5} A_{5} / \delta_{5}+\lambda_{6} A_{6} / \delta_{6}+{ }^{h_{\infty}, c} S_{c} / 2}
\end{aligned}
$$

The thermal conductivity and volume heat capacity of the wick are shown in Eqs. (14-15).

$$
\begin{aligned}
& \lambda_{m}=\frac{\lambda_{l}\left[2 \lambda_{l}+\lambda_{s}-2(1-\varepsilon)\left(\lambda_{l}-\lambda_{s}\right)\right]}{2 \lambda_{l}+\lambda_{s}+(1-\varepsilon)\left(\lambda_{l}-\lambda_{s}\right)} \\
& (\rho c)_{m}=(1-\varepsilon)(\rho c)_{s}+\varepsilon(\rho c)_{l}
\end{aligned}
$$

Where $\lambda_{l}$ represents the thermal conductivity of liquid metal mercury, $\mathrm{W} /(\mathrm{m} \cdot \mathrm{K}) ; \lambda_{s}$ represents the thermal conductivity of wick wire mesh, W / (m $\cdot \mathrm{K}) ; \varepsilon$ represents the porosity of wick. 
Longo Kutta method was used to solve the above equations.

\section{Results and discussion}

The parameters of mercury heat pipe in this study are shown in Table 1.

Table 1 Structural parameters of mercury heat pipe[15]

\begin{tabular}{ll}
\hline Parameter & Value \\
\hline Material of heat pipe wall & $316 \mathrm{~L}$ \\
Material of wick structure & $316 \mathrm{~L}$ \\
Thickness of wick $(\mathrm{mm})$ & 0.247 \\
Thickness of heat pipe wall $(\mathrm{mm})$ & 2.5 \\
Outer diameter of heat pipe $(\mathrm{mm})$ & 25 \\
Porosity of the wick structure & 0.7 \\
Length of the evaporator $(\mathrm{mm})$ & 950 \\
Length of the insulation section $(\mathrm{mm})$ & 320 \\
Length of the condenser $(\mathrm{mm})$ & 480 \\
\hline
\end{tabular}

\subsection{Validation of the mercury heat pipe mode}

In order to verify the effectiveness of the calculation model, the calculation result data are compared with the experimental data of mercury heat pipe in reference [17]. Fig. 2 shows the comparison between the calculated result data and the experimental data.The calculated result data is in good agreement with the experimental data, especially the temperature data of the evaporator. The temperature calculated result data of the adiabatic section and the condenser are slightly higher than the experimental data, which is mainly due to the heat loss in the adiabatic section during the heat pipe experiment.

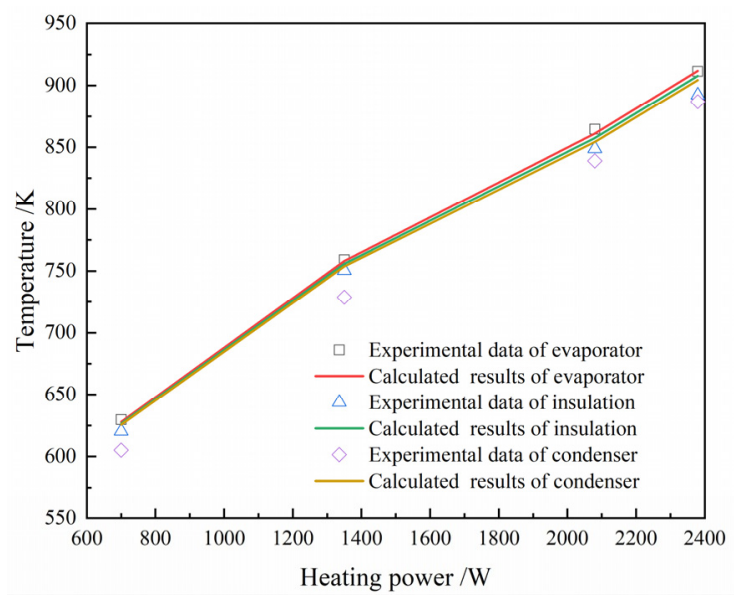

Fig. 2. Comparison of calculated and experimental temperature data of heat pipe

\subsection{Start-up time analysis of the mercury heat pipe}

Fig. 3 shows the temperature change of the condensation section with time under $700 \mathrm{~W}$ heating power. Since the temperature of the condensator is low in the early start-up stage of heat pipe, most of the heat is stored in the heat pipe and the temperature of the heat pipe rises rapidly. With the increase of the temperature of the heat pipe, the output heat of the heat pipe also increases, and only a small part of the input heat is used for the heating of the heat pipe itself, so the temperature rise of the heat pipe slows down, and finally tends to a stable value.Because the time for the heat pipe to be completely stable is very long, it is considered that the heat pipe is stable when the temperature change of the heat pipe is not more than $0.1 \mathrm{~K}$ within $1 \mathrm{~min}$. The start-up time of the mercury heat pipe is 60 min as clearly shown in Fig. 3. The mercury heat pipe does not show a huge temperature difference in the early stage of start-up, which is different from alkali metal $\mathrm{Na}$, $\mathrm{K}$ and Li heat pipes. This is mainly because Mercury heat pipe can form continuous flow at room temperature.

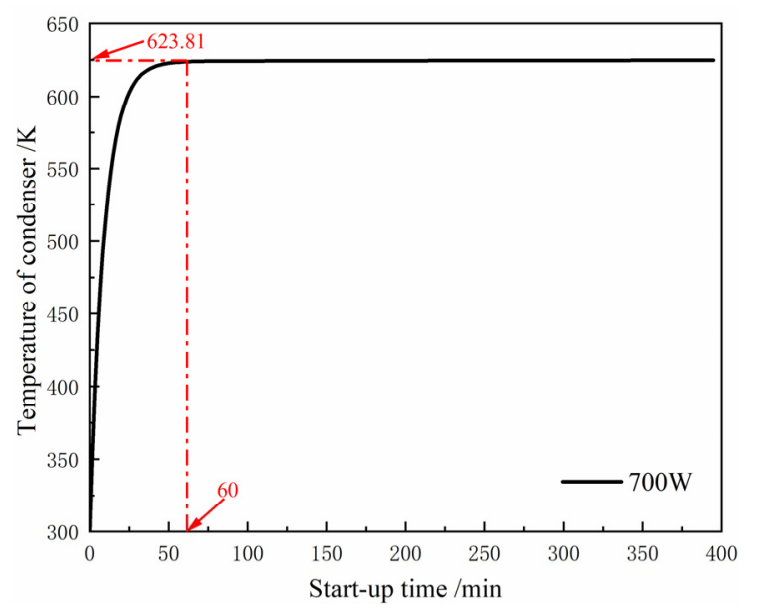

Fig. 3. The temperature of the heat pipe condenser for different time

Fig. 4 shows the effect of different heating power on the start-up time of mercury heat pipe. With the increase of heating power, the start-up time of heat pipe also increases. When the heating power increases from $700 \mathrm{~W}$ to $2800 \mathrm{~W}$, the start-up time has increased by $22 \%$.

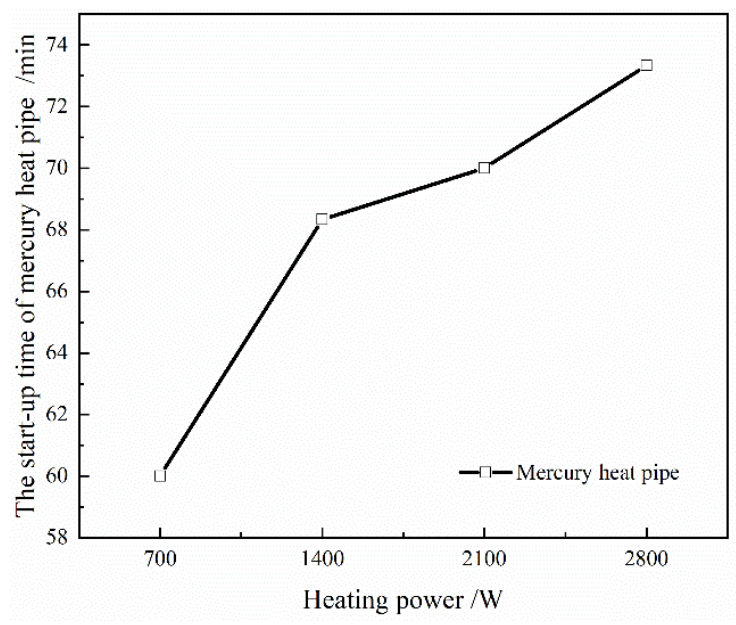

Fig. 4. The start-up time of heat pipe for different heating power

Fig. 5 shows the effect of different wall thickness on the start-up time of mercury heat pipe under different heating power for the same inner diameter. As the increase of the wall thickness, the heat storage capacity of the mercury heat pipe increases accordingly. Therefore, the 
start-up time of mercury heat pipe increases with the increase of wall thickness. The start-up time increases by $133 \%$ when the wall thickness increase from $1 \mathrm{~mm}$ to 4 $\mathrm{mm}$.

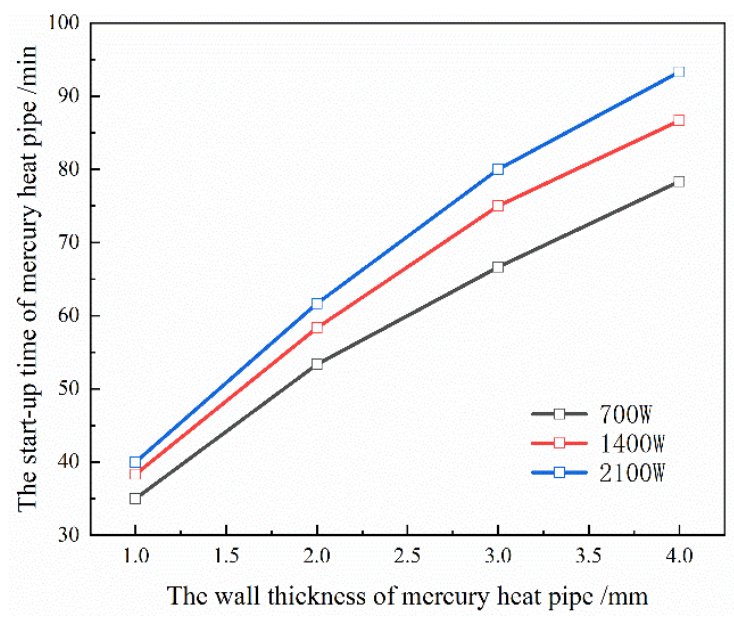

Fig. 5. The start-up time of heat pipe for different wall thickness

Fig. 6 shows the influence of different wick thickness on the start-up time of mercury heat pipe under different heating power for the same inner diameter of the heat pipe. Similar to increasing the wall thickness, increasing the thickness of the wick will also increase the heat storage capacity of the mercury heat pipe, and the start-up time is increased accordingly. The start-up time increased by $33 \%$ when the wick thickness increases from $0.25 \mathrm{~mm}$ to $2 \mathrm{~mm}$.

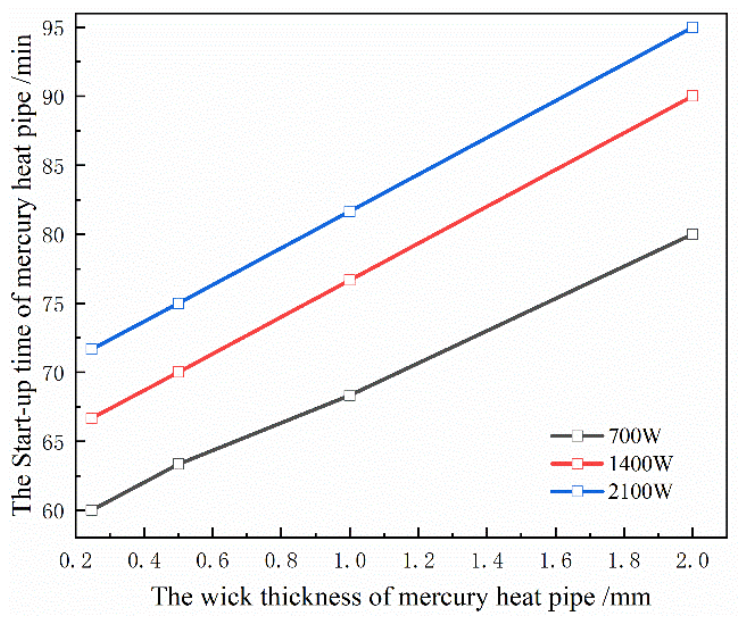

Fig. 6. The start-up time of heat pipe for different wick thickness

Fig. 7 shows the influence of different porosity of wick on the start-up time of mercury heat pipe under different heating power. The change of porosity will change the physical properties of the wick. When the porosity changes from 0.4 to 0.95 , the start-up time of the heat pipe decreases by $4.5 \%$. This means that the porosity has little effect on the start-up time of mercury heat pipe.

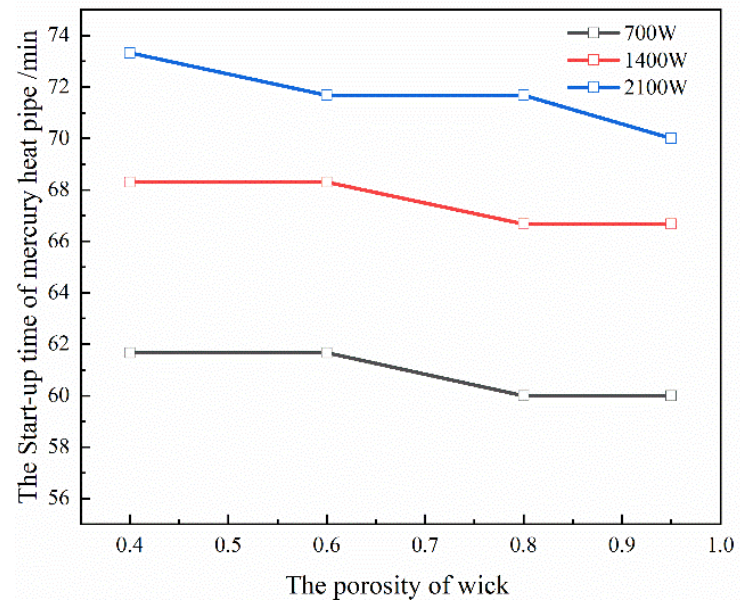

Fig. 7. The start-up time of heat pipe for different porosity of wick

Fig. 8 shows the effect of different condensing section length on the start-up time of mercury heat pipe under different heating power. Although the increase of the condensation section will increase the heat storage of the heat pipe itself, thus increasing the start-up time, however, it will reduce the thermal resistance, thus reducing the steady-state temperature of the heat pipe and reducing the start-up time. From the calculation results, the start-up time of the heat pipe decreases with the increase of the condensing section. When the condensing section increases from $700 \mathrm{~mm}$ to $1500 \mathrm{~mm}$, the start-up time decreases by $44.8 \%$.

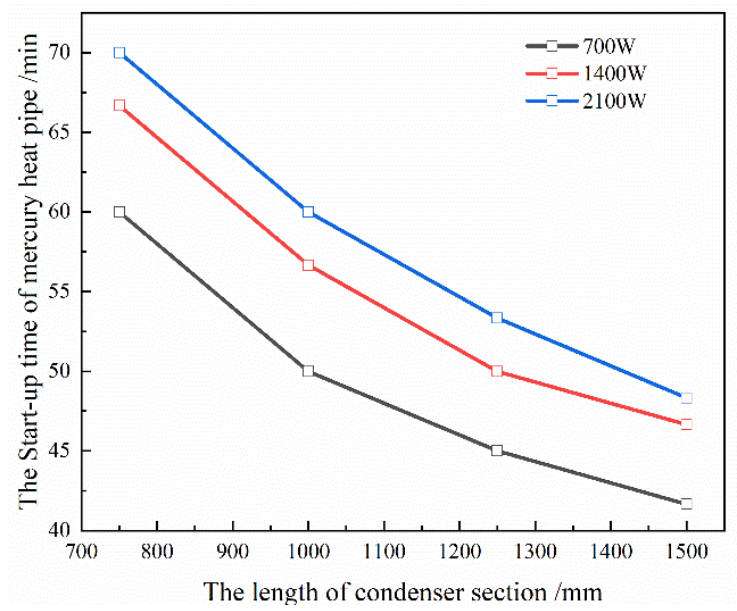

Fig. 8. The start-up time of heat pipe for different condenser length

\subsection{Thermal resistance analysis of the mercury heat pipe on steady-state}

Fig. 9 shows the effect of different heating power on the thermal resistance of mercury heat pipe. With the increase of heating power, the steady-state working temperature of heat pipe also increases. As the thermal conductivity of heat pipe material is related to temperature, the thermal resistance of heat pipe will change with the change of temperature. when the heating power changes from $700 \mathrm{~W}$ to $2100 \mathrm{~W}$, the thermal resistance of heat pipe decreases by $17.1 \%$ 


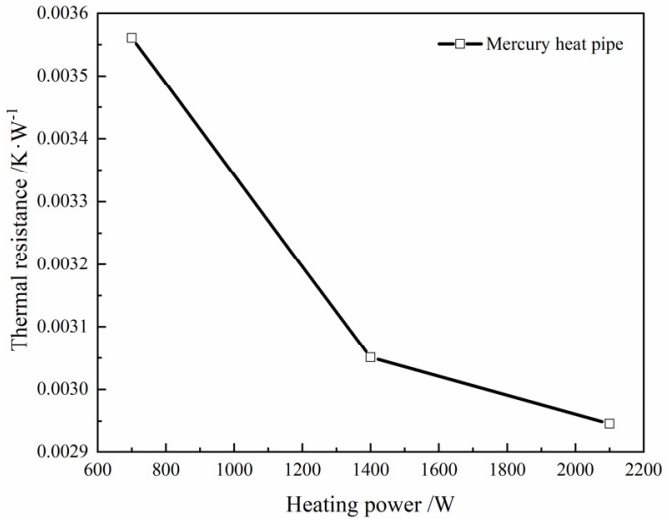

Fig. 9. The thermal resistance of heat pipe for different heating power

Figure. 10 shows the effect of different wall thickness on the thermal resistance of mercury heat pipe for the same inner diameter. With the increase of the wall thickness, the heat dissipation area of the heat pipe increases and the thermal resistance R7 will decrease, though the radial thermal resistance inside the heat pipe increases. the total thermal resistance of the heat pipe will decrease, which can be seen clearly from the Figure 10. When the wall thickness increases from $1 \mathrm{~mm}$ to $4 \mathrm{~mm}$, the thermal resistance decreases by $20.2 \%$.

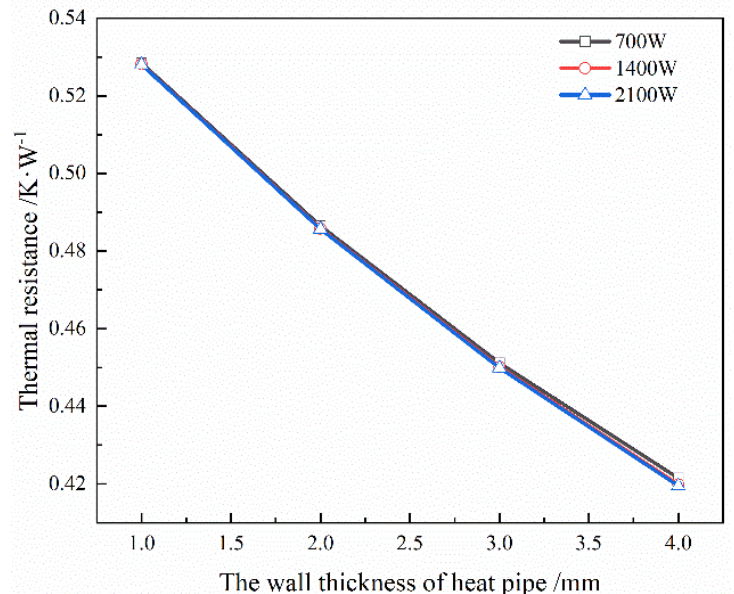

Fig. 10. The thermal resistance for different wall thickness of heat pipe

Fig. 11 shows the effect of different wick thickness on the thermal resistance of mercury heat pipe. With the increase of the wick thickness, the thermal resistance increases. When the wick thickness increases from $0.25 \mathrm{~m}$ to $2 \mathrm{~mm}$, the thermal resistance increases by $1.2 \%$.

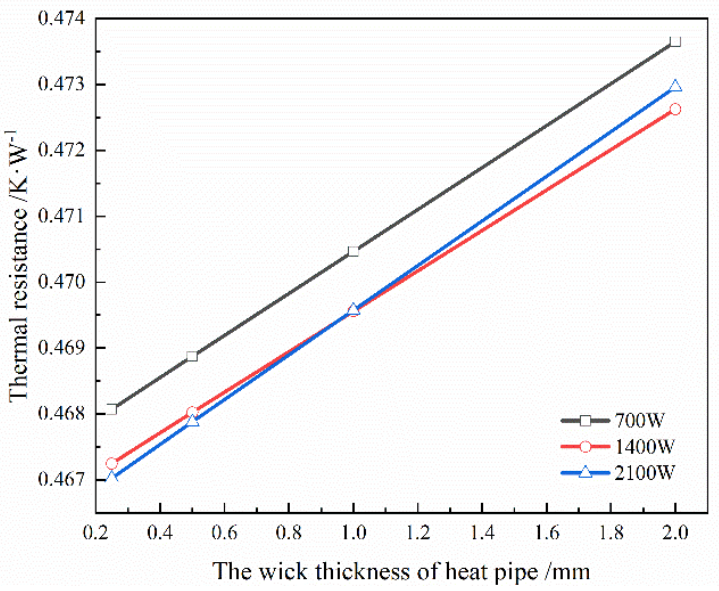

Fig. 11. The thermal resistance for different wick thickness of heat pipe

Fig. 12 shows the effect of different porosity on the thermal resistance of mercury heat pipe. As mercury has lower thermal conductivity than $316 \mathrm{~L}$ stainless steel, the thermal resistance of the wick increases with the increase of porosity. When the porosity changes from 0.4 to 0.95 , the thermal resistance increases by $0.1 \%$.

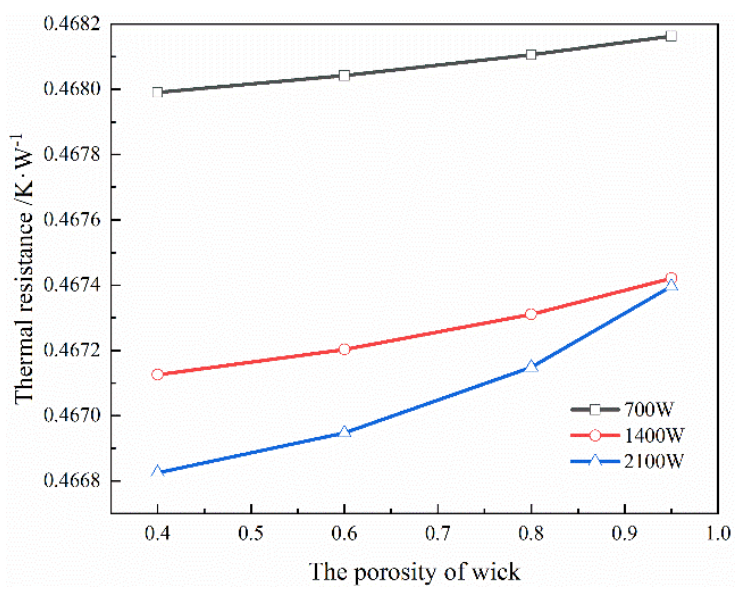

Fig. 12. The thermal resistance for different porosity of wick

Fig. 13 shows the effect of different condensing length on the thermal resistance of mercury heat pipe. With the increase of the condensator length of the heat pipe, the heat dissipation area of the heat pipe increases, and the thermal resistance of the heat pipe decreases. When the condensator length increases from $750 \mathrm{~mm}$ to $1500 \mathrm{~mm}$, the thermal resistance decreases by $27.8 \%$.

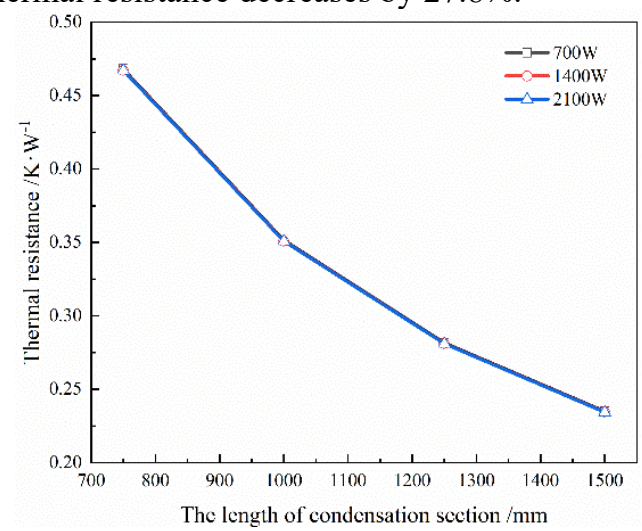

Fig. 13. The thermal resistance for different condensator length 


\section{Conclusion}

In this paper, a transient thermal network model for mercury heat pipe was established. The validity of the model was demonstrated by comparing with the experimental data in the literature, and the effects of heat pipe structure and heating power on the start-up time and thermal resistance were studied.The results are as follows:

(1) With the increase of heating power, the wall thickness and wick thickness, the start-up time of mercury heat pipe increases.the wall thickness has the greatest effect up to $133 \%$, while the heating power has the least effect only $17 \%$. The start-up time decreases with the increase of porosity or the length of condenser. The condenser length has a greater influence than the porosity on the start-up time.

(2) As the thickness or porosity of wick increases, the thermal resistance of heat pipe increases, but both of the factors have little effect on the thermal resistance, and the maximum influence is only $1.2 \%$. The increase of heating power, wall thickness and condenser length is beneficial to reduce the thermal resistance, and the condenser length has the greatest effect up to $27.8 \%$

(3) Among all the variables, increasing the thickness of wick is unfavorable to both start-up time and thermal resistance, while increasing condenser length is favorable to both start-up time and thermal resistance

\section{Acknowledgments}

Financial support from scientific research projects of Suzhou University (2019xhx033) and the Suzhou University Teacher Application Ability Development Workstation (2018XJYY01) is acknowledged.

\section{References}

1. Phillips W M, Estabrook W C, Hsieh T M., 1976. Nuclear thermionic power system for spacecraft. Pasadena, CA: Jet Propulsion Laboratory.

2. Wang D C, Xia Z Z, Wu J Y, et al., 2005. Study of a novel silica gel-water adsorption chiller. part i. design and performance prediction. International journal of refrigeration. 28(7).

3. Critoph R E., 2002. Multiple bed regenerative adsorption cycle using the monolithic carbonammonia pair. Applied Thermal Engineering. 22(6), 667-677.

4. Glass D E, Camarda C J, Merrigan M A., 1998. Refractory composite/heat pipe cooled leading edge and method for fabrication. U.S. Patent No. 5720339.

5. Glass D E, Merski N R, Glass C E., 2002. Airfram Research and technology for Hypersonic Airbreathing Vehicles. AIAA 2002-5137.

6. Gibson M A, Poston D I, Mcclure P R. et al., 2018. Kilopower reactor using stirling technolog $\mathrm{Y}$ (KRUSTY) nuclear ground test results and lessons learned, NASA/TM-2018-219941.

7. Liu X, Zhang R, Liang Y. et al., 2020. Core thermalhydraulic evaluation of a heat pipe cooled nuclear reactor, Annals of Nuclear Energy. 142.

8. Anand A R., 2019. Investigations on effect of evaporator length on heat transport of axially grooved ammonia heat pipe. Applied Thermal Engineering. 150, 1233-1242.

9. Miao S, Sui J, Zhang Y. et al., 2020. Experimental study on thermal performance of a bent copper-water heat pipe. International Journal of Aerospace Engineering. 4, 1-10.

10. Zhang kai, Yue kai, Yan X K, et al., (2020). Study on isothermal characteristics of gravity cesium heat pipe. Acta Metrologica Sinica. 41(1), 26-31.

11. Wang C L, Liu X, Liu M H., et al., 2021. Experimental study on heat transfer limit of high temperature potassium heat pipe for advanced reactors. Annals of Nuclear Energy. 151.

12. Teng W, Wang X, Zhu Y., 2020. Experimental investigations on start-up and thermal performance of sodium heat pipe under swing conditions. International Journal of Heat and Mass Transfer. 152, 119505.1-119505.8.

13. Tournier J M, El-Genk M S., 2003. Startup of a horizontal lithium-molybdenum heat pipe from a frozen state. International Journal of Heat \& Mass Transfer. 46(4), 671-685.

14. Zuo Z J, Faghri A., 1998. A network thermodynamic analysis of the heat pipe. International Journal of Heat and Mass Transfer. 41(11), 1473-1484.

15. Zhang J, Zhang H., 2000. Heat pipe technology and engineering application. Beijing, Chemical Industry Press.156-158.(in Chinese) 